\title{
GT-2002-30481
}

\section{MEASUREMENT AND ANALYSIS OF INGESTION THROUGH A TURBINE RIM SEAL}

\author{
O. Gentilhomme, N. J. Hills, A. B. Turner \\ Thermo-Fluid Mechanics Research Centre \\ University of Sussex \\ Brighton, East Sussex, BN1 9QT, UK
}

\author{
J. W. Chew \\ Fluids Research Centre \\ School of Engineering \\ University of Surrey \\ Guildford, Surrey, GU2 7XH, UK
}

\begin{abstract}
Experimental measurements from a new single stage turbine are presented. The turbine has 26 vanes and 59 rotating blades with a design point stage expansion ratio of 2.5 and vane exit Mach number of 0.96 . A variable sealing flow is supplied to the disc cavity upstream of the rotor and then enters the annulus through a simple axial clearance seal situated on the hub between the stator and rotor. Measurements at the annulus hub wall just downstream of the vanes show the degree of circumferential pressure variation. Further pressure measurements in the disc cavity indicate the strength of the swirling flow in the cavity, and show the effects of mainstream gas ingestion at low sealing flows. Ingestion is further quantified through seeding of the sealing air with nitrous oxide or carbon dioxide and measurement of gas concentrations in the cavity. Interpretation of the measurements is aided by steady and unsteady computational fluid dynamics solutions, and comparison with an elementary model of ingestion.
\end{abstract}

\section{INTRODUCTION}

To avoid overheating of turbine discs, ingestion of hot turbine gas through turbine rim seals must be prevented or limited. This can be achieved by channelling cool, high pressure air from the compressor to the turbine where it is ejected back into the main gas path through the rim seals. If sufficient sealing air is supplied, then inflow of hot gas through the rim seals will be completely suppressed. However, to minimise performance losses, the sealing flows generally need to be kept as low as possible. With the flows involved being complex and unsteady, the seal flows possibly having significant effects on blade passage aerodynamics and performance, and running seal clearances often subject to uncertainty, optimisation of sealing flows presents a considerable challenge in turbomachinery design. While recent research has resulted in considerable progress in understanding these flows, significant questions and shortcomings in current predictive methods remain.

The importance of circumferential pressure gradients in the annulus flow for rim seal ingestion was noted by Campbell [1]. This was confirmed experimentally by several workers. For example Abe et al [2], Kobayashi et al [3], Phadke and Owen [4], Dadkhah et al [5], Hamabe and Ishida [6] and Chew et al [7] have performed experiments with various asymmetries in the annulus caused by guide vanes or other stationary disturbances. The conclusion may be drawn from these results that, at engine conditions, circumferential pressure asymmetries are the primary cause of ingestion. Chew et al reported both experimental and 3D computational fluid dynamics (CFD) results and concluded that inertial effects associated with the swirl component of velocity had an important influence on the flow. The combined influence of pressure asymmetries due to stationary vanes and rotating blades was noted by Green and Turner [8] and Bohn et al [9] who measured ingestion with both vanes and blades present. Bohn et al also presented unsteady CFD solutions showing some qualitative agreement with their data. The need to develop further understanding of the combined effect of rotating and pressure asymmetries was apparent from this work.

Two very recent, concurrent, but independent, studies are also relevant to the present paper. Both Roy et al [10] and Hills et al [11] concluded that predictive methods for rim seal ingestion must take account of the unsteady nature of the flow. Roy et al measured pressures and ingestion in a turbine rig. Based on their unsteady pressure measurements and the observation that steady CFD models did not correctly predict ingestion they concluded that the unsteadiness was playing an important part in the ingestion process. Hills et al showed that an unsteady CFD model gave considerably better agreement with previously published experimental ingestion data than steady models. For the conditions considered it was shown that 
the circumferential pressure asymmetry due to rotating blades had a large influence on ingestion despite being considerably smaller than the pressure asymmetry due to the stationary vanes. This was explained by considering inertial effects on the flow and the fact that the swirl velocity of the air was much closer to the rotor speed than to that of the vanes. An elementary model, taking some account of these effects was also shown to capture the experimental trends.

In this paper experimental measurements of rim seal ingestion from a new single stage turbine rig are presented and used to evaluate predictions using steady and unsteady CFD solutions for the main annulus flow and a more elementary model of rim seal ingestion. This level of modelling is considered practical for use within design time scales, yet offers significant advances over methods commonly used at present. The experimental rig and the measurements are described in the next section. The CFD studies are then presented and compared to measurements in section 3 . The ingestion model, which follows that presented by Hills et al, is given, and results compared with data in section 4 . The main conclusions from this study are then summarised in section 5 .

\section{NOMENCLATURE}

c vane chord

$\mathrm{C}_{\mathrm{d}}$ discharge coefficient

$\mathrm{C}_{\mathrm{h}}$ loss coefficient

$\mathrm{C}_{\mathrm{pa}} \quad$ static pressure coefficient $=\left(\mathrm{p}_{\theta}-\mathrm{p}_{\text {aver }}\right) /\left(\mathrm{P}_{03}-\mathrm{p}_{\text {aver }}\right)$

$\mathrm{C}_{\mathrm{w}} \quad$ non-dimensional flow rate $=\mathrm{m} /\left(\mu \mathrm{r}_{0}\right)$

$\mathrm{G} \quad$ gap ratio $=\mathrm{s} / \mathrm{r}_{0}$

$\mathrm{G}_{\mathrm{c}} \quad$ clearance ratio $=\mathrm{s}_{\mathrm{c}} / \mathrm{r}_{0}$

$\mathrm{k}$ axial decay coefficient

1 length scale for seal flow

$\mathrm{m}$ mass flow rate

M Mach number

$\mathrm{N}$ number of vanes/blades

p static pressure

$\mathrm{P}$ total pressure

$r$ radius

$\mathrm{r}_{0} \quad$ cavity outer radius

$\mathrm{R}$ radius ratio $\left(=\mathrm{r} / \mathrm{r}_{0}\right)$

$R_{\mathrm{ez}} \quad$ vane exit Reynolds number $=\left(\rho \mathrm{U}_{\mathrm{res}} \mathrm{c}\right) / \mu$

$\mathrm{R}_{\mathrm{e} \theta} \quad$ rotational Reynolds number $=\left(\rho \Omega \mathrm{r}_{0}{ }^{2}\right) / \mu$

S cavity width

$\mathrm{s}_{\mathrm{c}} \quad$ axial clearance

U velocity

$\mathrm{U}_{\mathrm{e}} \quad$ axial component of external flow

$\mathrm{U}_{\mathrm{m}} \quad$ average velocity through seal gap $=\mathrm{m}_{\mathrm{c}} /\left(2 \pi \rho \mathrm{s}_{\mathrm{c}} \mathrm{r}_{0}\right)$

$\mathrm{V}_{\theta} \quad$ swirl (or tangential velocity)

$\beta \quad$ core-swirl ratio $=\mathrm{V}_{\theta, \text { core }} /\left(\Omega \mathrm{r}_{0}\right)$

$\Delta \mathrm{p} \quad$ pressure difference across seal

$\eta_{\mathrm{R}}$ cavity concentration at $\mathrm{R}$

$\eta_{\mathrm{c}} \quad$ coolant flow concentration

$\eta_{\infty} \quad \mathrm{CO}_{2}$ concentration in the ambient air

$\lambda$ turbulent flow parameter $=\mathrm{C}_{\mathrm{w}} \mathrm{Re}_{\theta}{ }^{-4 / 5}$ $\varphi \quad$ sealing effectiveness

$\rho$ density

$\Omega \quad$ rotational speed

\section{Subscripts}

03 upstream of NGV

04 downstream of rotor

aver averaged downstream of $\mathrm{NGV}$

c coolant

e external flow

res resultant value

$\mathrm{r}, \theta, \mathrm{z}$ radial, tangential and axial directions

\section{EXPERIMENTS}

\subsection{Experimental apparatus}

The test facility consists of a complete axial turbine stage based on a modified Gnome helicopter engine (HP1200 Power Turbine Module) enclosed in an annular channel through which the mainstream air flows. A close-up view of the rig is shown in Fig. 1.

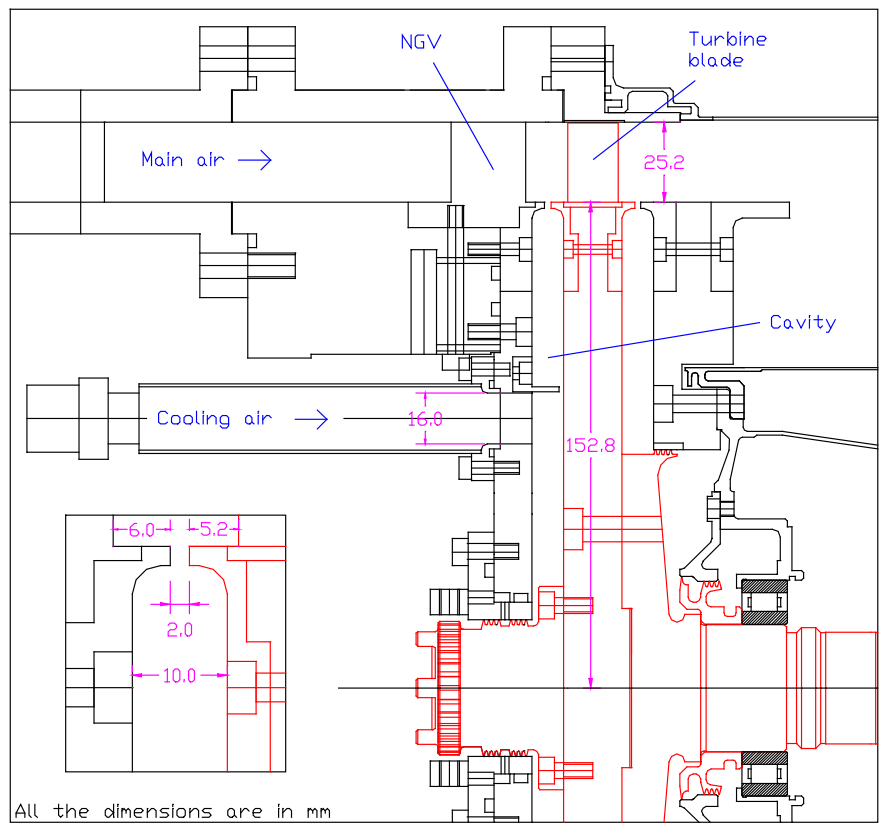

Fig. 1. Experimental rig

The rotor-stator assembly is made up of titanium blisk with 59 twisted blades machined into its periphery and of 26 constant section aluminium Nozzle Guide Vanes (NGVs). The exit angle of the NGVs is $70^{\circ}$ and the radius of the disc is 152.8 $\mathrm{mm}$. Both the NGV and rotor blade heights are $25 \mathrm{~mm}$ and the axial distance between the aerofoil rows is $13.2 \mathrm{~mm}$. For the tests reported in this paper, the wheel-space width was $10 \mathrm{~mm}$ $(\mathrm{G}=0.065)$ and a simple axial clearance of $2 \mathrm{~mm}\left(\mathrm{G}_{\mathrm{c}}=0.013\right)$ with a radial extent of $2 \mathrm{~mm}$ was fitted at the rim of the cavity. 
The stator and rotor faces are completely flat and the edge of the stator shroud is located $6 \mathrm{~mm}$ downstream of the NGV trailing edge.

Depending on the operating conditions tested, the annulus air is either supplied by a Rolls-Royce Dart centrifugal compressor capable of generating mass flow rates up to 10.5 $\mathrm{kg} / \mathrm{s}$ at a pressure of 3.3 bar absolute (Turner et al, [12]) or a Keith Blackman compressor rated at $1.1 \mathrm{~kg} / \mathrm{s}$ with 1.6 bar absolute. The turbine power $(\approx 360 \mathrm{~kW}$ at the design point $)$ is dissipated by a Heenan and Froude DPY590 water-cooled dynamometer connected to the rotor-stator system via a Gnome Main Reduction Gearbox (3.25:1). Figure 2 shows the turbine characteristic and the two operating conditions considered here (OC1 and OC2). Note that in this figure the mass flow was estimated from total and static pressure taps located upstream of the NGVs. This is because there is some uncertainty in the Venturi tube measurements at pressure ratios 1.6 and 2 due to an air leak. This did not affect conditions $\mathrm{OC} 1$ or OC2 and elsewhere in the paper the Venturi measurements have been used. Conditions OC1 and OC2 features are summarised in Table 1. Owing to the high heat dissipation by the dynamometer at the design point and the limited volume of water available to cool it, more than one run was necessary to obtain a satisfactory range of sealing air conditions. This led to slightly different mainstream conditions at the design speed, hence the scattering of points at the turbine characteristic.

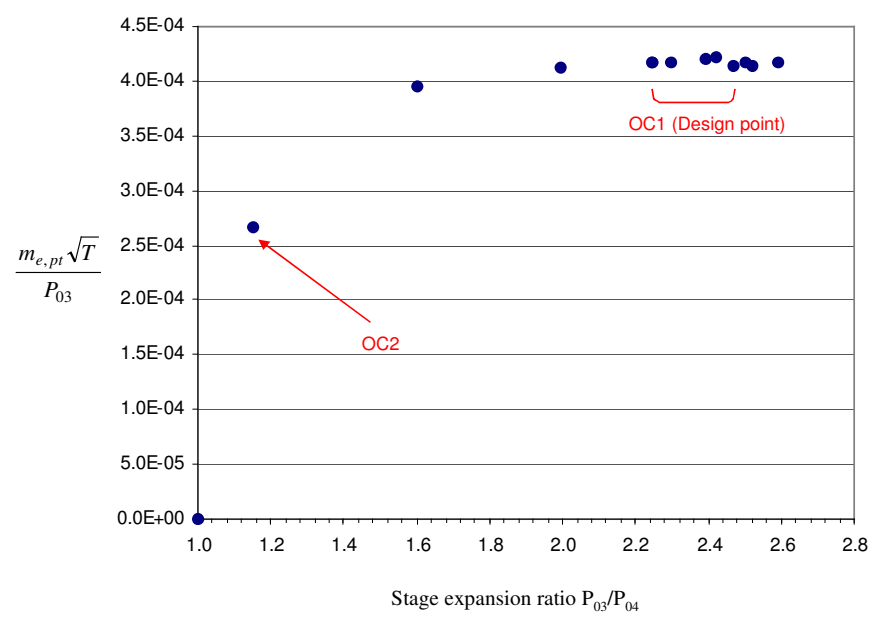

Fig. 2. Turbine characteristic

A separate source of air, either a hydrovane compressor (rated $0.1 \mathrm{~m}^{3} / \mathrm{s}$ at 8 bar absolute) or a ZT250 type ATLAS COPCO compressor (up to $0.8 \mathrm{~kg} / \mathrm{s}$ with a maximum outlet pressure of 7.5 bar absolute), provided the cooling air, which was admitted to the wheelspace cavity through 3 equi-spaced tubes of inside diameter $16 \mathrm{~mm}$ at a radius of $84.75 \mathrm{~mm}$ $(\mathrm{R}=0.55)$. Prior to its introduction into the cavity, the cooling flow is seeded with a tracing gas and the concentration is measured at 4 different radial positions on the stator surface
$(\mathrm{R}=0.4,0.71,0.88$ and 0.92$)$ by means of a gas analyser. At $\mathrm{OC} 1$, the seeding gas employed was nitrous oxide (NO) whereas carbon dioxide $\left(\mathrm{CO}_{2}\right)$ was preferred at $\mathrm{OC} 2$, the sampled concentrations being measured with an IRGA 120 GP Instrumentation and a Leybold Heareus gas analysers respectively. The uncertainty of both systems is estimated to be $+/-2 \%$.

Table 1: Operating conditions investigated

\begin{tabular}{|c|c|c|}
\hline & OC1 & OC2 \\
\hline \multicolumn{3}{|l|}{ External flow } \\
\hline NGV exit Mach number M & 0.963 & 0.390 \\
\hline Exit NGV Reynolds number $\mathrm{R}_{\mathrm{ez}}$ & $6.23 \times 10^{5}$ & $1.77 \times 10^{5}$ \\
\hline Stage Expansion Ratio $\mathrm{P}_{03} / \mathrm{P}_{04}$ & 2.50 & 1.14 \\
\hline \multicolumn{3}{|l|}{ Disc } \\
\hline Rotational speed $\Omega$ & $13,500 \mathrm{rev} / \mathrm{min}$ & $6,550 \mathrm{rev} / \mathrm{min}$ \\
\hline Rotational Reynolds number $\mathrm{R}_{\mathrm{e} \theta}$ & $2.83 \times 10^{6}$ & $9.04 \times 10^{5}$ \\
\hline \multicolumn{3}{|l|}{ Temperatures } \\
\hline Annulus air & $420 \mathrm{~K}$ & $355 \mathrm{~K}$ \\
\hline Cooling air & $300 \mathrm{~K}$ & $300 \mathrm{~K}$ \\
\hline Cooling/Annulus Density Ratio & 1.41 & 1.2 \\
\hline
\end{tabular}

The circumferential variation of the static pressure in the mainstream flow is determined using 11 tappings in the annulus hub end wall drilled at $1.5^{\circ}$ intervals over approximately 1.1 NGV pitch and located $1.5 \mathrm{~mm}$ downstream of the vanes. Pressures inside the wheel-space cavity are also measured by means of 12 static pressure taps equally distributed on 2 angular positions to check the flow axi-symmetry. The taps are located at the radius ratios $\mathrm{R}=0.4,0.71,0.805,0.88,0.92$ and 0.96 on the stator surface. These pressures are measured with a Scanivalve system.

\subsection{Results}

Figure 3 shows the circumferential variation of the annulus pressure measured downstream of the NGVs at the design point (OC1) for different seal-to-annulus velocity ratios $U_{m} / U_{e}$. The annular pressure coefficient $\mathrm{C}_{\mathrm{pa}}$ is defined as the difference between the measured static pressure and the average of the measured static pressures non-dimensionalised by the NGV exit dynamic head $\left(\mathrm{P}_{03}-\mathrm{p}_{\text {aver }}\right)$. The maximum uncertainty of $\mathrm{C}_{\mathrm{pa}}$ has been estimated to be $0.14 \%$ throughout all the experiments. In this figure are also included the guide vane profiles and the positions of the 11 pressure tappings. Note that the lines joining the data points in this figure are obtained from curve fits to the data. It can be seen that the non-dimensionalised pressure profile is fairly independent of the quantity of cooling air introduced into the cavity. Thus as $\mathrm{U}_{\mathrm{m}} / \mathrm{U}_{\mathrm{e}}$ increases, the pressure level in the annulus flow rises while the pressure asymmetry which is thought to be the dominant ingestion driving mechanism is only slightly affected. A comparison with the annulus pressure distribution obtained at $\mathrm{OC} 2$ for a velocity 
ratio of 0.048 is also provided. For both design and off-design operating conditions, the pressure asymmetry measured $1.5 \mathrm{~mm}$ downstream of the NGVs corresponds to about $20 \%$ of the dynamic head.

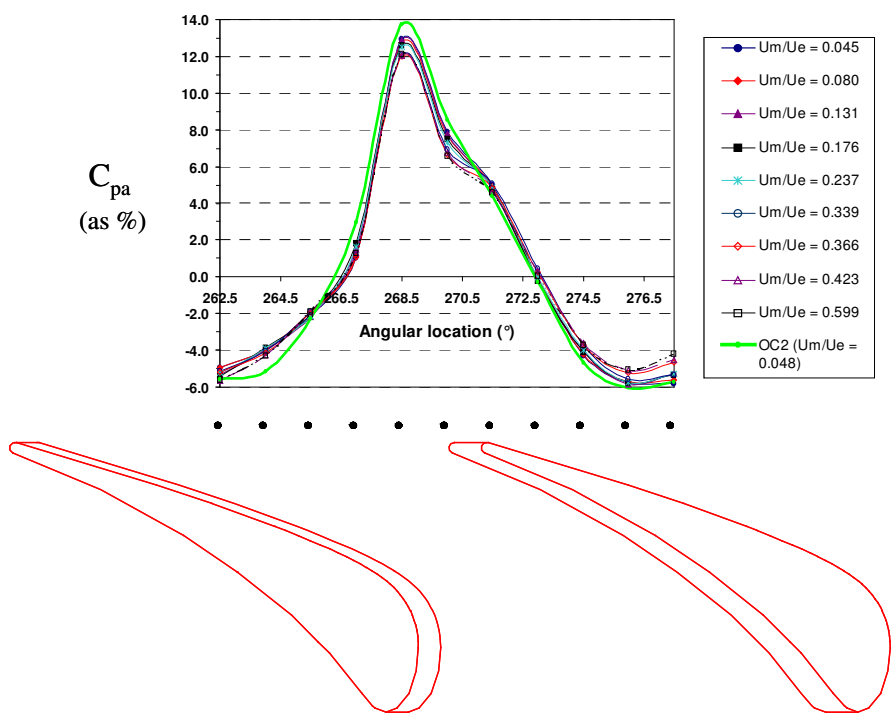

Fig. 3. Annulus pressure measurements

The effect of mainstream gas ingestion on the wheel-space pressure measurements can be observed in Fig.4. In the upper part of the cavity where the tangential velocity of the rotating core $\mathrm{V}_{\theta \text {,core }}$ is much higher than the radial component of velocity $\mathrm{V}_{\mathrm{r}, \text { core }}$, the radial momentum equation is reduced to:

$$
\frac{\partial p}{\partial r}=\frac{\rho V_{\phi, c o r e}^{2}}{r}
$$

Assuming $V_{\theta, \text { core }}=\beta \times \Omega r$, with $\beta$ and density constant, the integration of Eq. (1) with respect to $r$ gives:

$$
\frac{p_{R_{2}}-p_{R_{1}}}{\frac{1}{2} \rho \Omega^{2} r_{0}{ }^{2}}=\beta^{2}\left(R_{2}^{2}-R_{1}^{2}\right)
$$

where $p_{R 1}, p_{R 2}$ denote the static pressures when $R=R_{1}$ and $R_{2}$ respectively. Using the pressure measurements in the cavity, it is then possible to estimate the core cavity swirl ratio. Note however that, since $\beta$ may vary with radius, this method does involve some approximation. The results are shown in Fig.4 for OC2. Here $\beta$ is plotted against the non-dimensionalised flow parameter $\lambda \mathrm{R}^{-2.6}\left(=\mathrm{C}_{\mathrm{w}} \mathrm{Re}_{\theta}{ }^{-0.8} \mathrm{R}^{-2.6}\right)$. When this parameter is equal to 0.22 the supplied sealing flow is equal to the free disc pumping flow as given by von Karman's [13] solution. A comparison has been made with the LDA measurements of Pincombe and El Oun [14] and the numerical results of
Vaughan [15] carried out with non-swirled axi-symmetric external flow over the rotor-stator cavity.

As expected, the level of core rotation decreases with increasing values of the flow parameter $\lambda$. At low sealing flows, the tangential velocities calculated at the 3 radial locations $\mathrm{R}=0.92,0.88$ and 0.805 are well above the data obtained by $\mathrm{El}$ Oun and Pincombe - sometimes even higher than the value $\beta=0.426$ predicted with no throughflow. The agreement is better as the radial position $\mathrm{R}$ decreases. This behaviour is a direct consequence of annulus flow ingestion affecting the cavity flow at low values of $\lambda$. Downstream of the NGVs, the annulus flow possesses a high tangential velocity $\left(V_{\theta} / \Omega r_{o}=1.32\right)$ and with part of this flow being ingested through the rim seal clearance the swirl of the rotating core is increased. For the highest values of $\lambda$, where sealing flow rates are higher and ingestion is suppressed, the calculated swirl ratio is relatively insensitive to the considered radial position $\mathrm{R}$ and closer to the LDA measurements of El Oun and Pincombe.

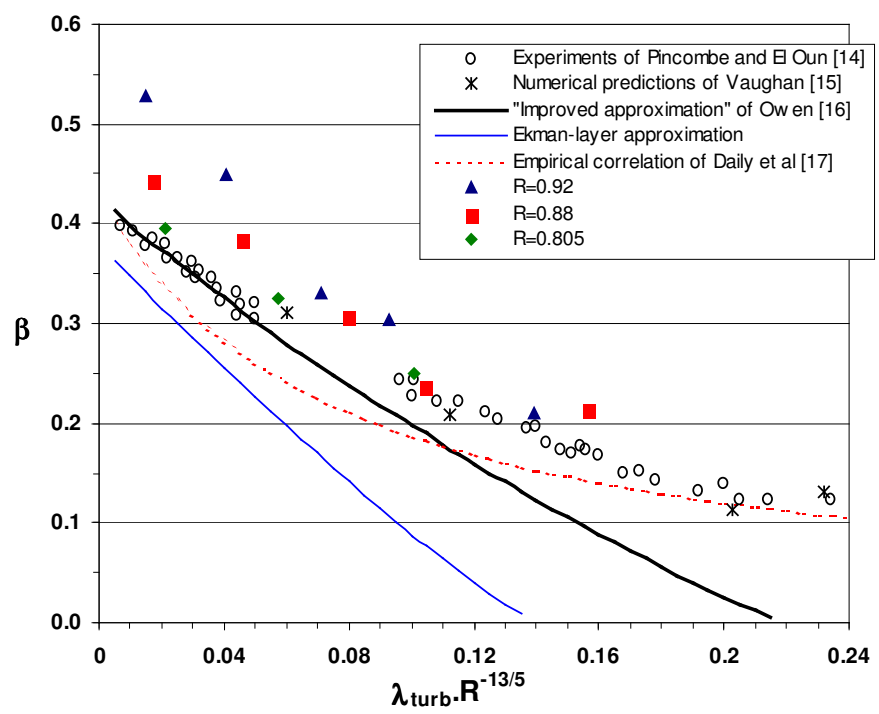

Fig. 4. Cavity swirl calculated from pressure measurements (OC2)

Figure 5 shows the variation of sealing effectiveness $\varphi$ against the velocity ratio $U_{m} / U_{e}$ for the two operating points investigated $\mathrm{OC} 1$ and $\mathrm{OC} 2$. The percentage sealing effectiveness is defined as:

$$
\varphi=\frac{\eta_{R=0.92}-\eta_{\infty}}{\eta_{c}-\eta_{\infty}} \times 100
$$

where $\eta_{R=0.92}$, and $\eta_{c}$ are respectively the gas concentrations of the air sampled at the location $\mathrm{R}=0.92$ on the stator surface in the cavity and of the cooling air. At OC2, since carbon dioxide is present in the ambient air (at a rate of about $300 \mathrm{ppm}$ ), it was 
necessary to introduce the parameter $\eta_{\infty}$ in the expression of $\varphi$. This concentration was measured at the end of the tests. At OC1, $\eta_{\infty}$ was zero. The variations of $\varphi$ for OC 1 and OC 2 are in reasonably good agreement supporting the suggestion that the velocity ratio $\mathrm{U}_{\mathrm{m}} / \mathrm{U}_{\mathrm{e}}$ is an appropriate correlating parameter. Use of the momentum ratio $\left(\rho_{\mathrm{c}} \mathrm{U}_{\mathrm{m}}{ }^{2} /\left(\rho_{\mathrm{e}} \mathrm{U}_{\mathrm{e}}{ }^{2}\right)\right.$ does not improve the collapse of data, but this may be due to other differences between $\mathrm{OC} 1$ and $\mathrm{OC} 2$. Note that, for the same value of $\mathrm{U}_{\mathrm{m}} / \mathrm{U}_{\mathrm{e}}$, the coolant flow rates for the two operating conditions differ by a factor of more than two.

$\varphi(\%)$

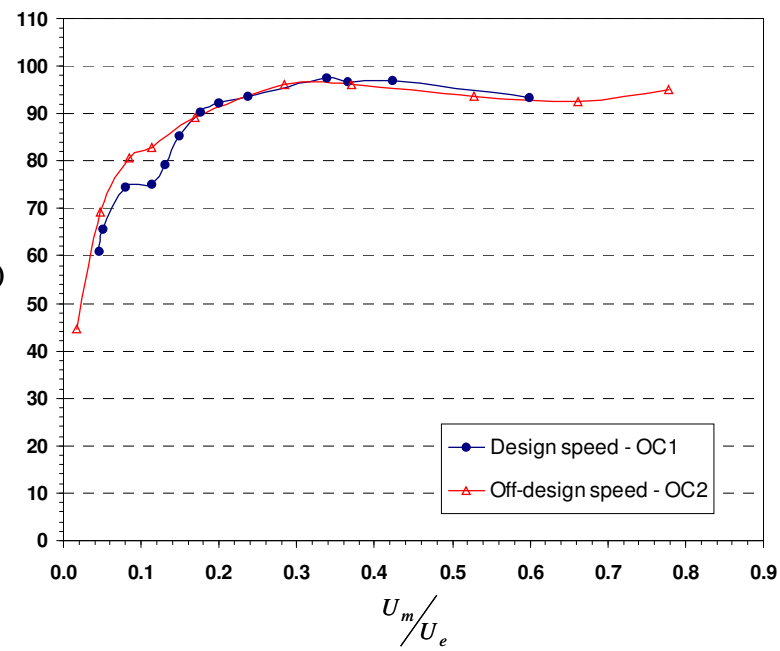

Fig. 5. Concentration measurements at $R=0.92$

\section{CFD MODELLING}

\subsection{Description of the mode}

CFD models for the flow in the main gas path annulus are described in this section. No account is taken of the sealing flows in these models, but the circumferential pressure asymmetries deduced from the CFD models will be used for the ingestion modelling in section 4.

Three different models based on the experimental rig are used and their features are given in Table 2. Model 1 does not include the rotor blades and assumes a steady flow in the stationary frame. Model 2 does not include the NGVs and assumes a steady flow in the rotating frame. Model 3 represents the whole turbine stage and calculates the unsteady flow using a sliding interface between the stationary and rotating parts. Since the sliding mesh process requires that the two interface boundaries are based on the same geometry, 27 NGVs and 54 rotor blades (i.e. 2 blades per vane) are modelled as opposed to 26 NGVs and 59 blades in the experimental rig. The computational domain is represented in Fig. 6. (In all the models, the inlet and outlet was extended to avoid difficulties with spurious reflections from the boundaries.) Within Gambit [18], the mesh was generated on the hub end wall of the annulus channel using quadrilateral cells and then extended in the radial direction up to the tip end wall by projecting the mesh node patterns of the hub-end-wall through the volume. Boundary layers were previously applied to the solid surfaces using 6 rows of cells on the vane and 3 rows on the blade with a growth rate of 1.2. This resulted in about 436,000 cells for the model 1 , 445,500 cells for model 2 and 636,500 for model 3.

Table 2: Summary of CFD models

\begin{tabular}{|c|c|c|c|}
\hline Model & Steady / Unsteady & $\mathrm{N}^{\circ}$ vanes & $\mathrm{N}^{\circ}$ blades \\
\hline 1 & Steady in stationary frame & 1 & 0 \\
\hline 2 & Steady in rotating frame & 0 & 1 \\
\hline 3 & Unsteady (sliding plane) & 1 & 2 \\
\hline
\end{tabular}

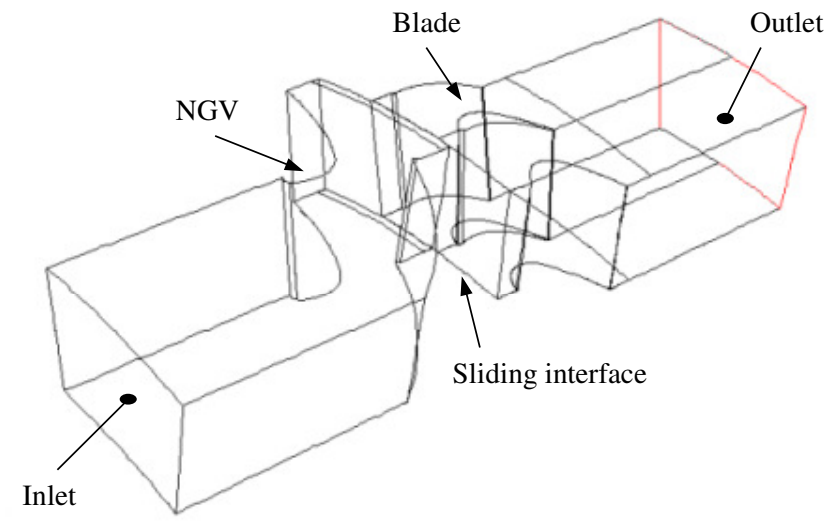

Fig. 6. Domain for the unsteady CFD model 3

The calculations were performed with Fluent 5.5 [19]. The governing equations (mass, momentum and energy) were solved using a segregated implicit solver and both the k- $\varepsilon$ (with a standard wall function treatment in the vicinity of the solid surfaces) and the Spalart-Allmaras turbulence models were tested. The models were run at the 2 operating conditions OC1 and OC2 previously described in this paper necessitating the use of the compressible ideal gas law for the fluid. At the inlet, the experimental mass flow (adjusted proportionally to the number of aerofoils present in the geometry) and the total temperature were specified while static pressure was specified at the outlet. For model 1, this pressure corresponds to the circumferential average of the pressure profile obtained experimentally $1.5 \mathrm{~mm}$ downstream of the NGV and was set in the CFD model at the hub of the annulus channel. The static pressure on the rest of the boundary was calculated assuming a radial equilibrium pressure distribution. For models 2 and 3, the pressure measured $40 \mathrm{~mm}$ downstream of the rotating blades on the outer casing of the annulus channel was used. For model 2, a flow angle corresponding to the exit angle of the NGV $\left(=70^{\circ}\right)$ was also specified at the inlet. Apart from the outlet of model 1, 
uniform boundary conditions were therefore assumed. The unsteady solution of model 3 was solved using time step sizes of 3 and $4 \mu$ s at OC1 and OC2 respectively. This led to a new rotor blade passing the NGV every 28 and 42 time steps.

The convergence of the steady solutions was checked by monitoring the conventional Fluent residuals of the continuity, momentum, energy and turbulence equations. For the unsteady model 3, this approach could be misleading and thus it was preferred to monitor the mass flow difference between the inlet and outlet of the geometry. The unsteady calculation was judged to be close to convergence when the parameter showed an oscillatory behaviour around 0 with the magnitude of the oscillations insignificant compared to the inlet mass flow.

\subsection{CFD results}

Figures 7 (a) and (b) show the circumferential variations of the annulus pressure at the design and off-design speed conditions $\mathrm{OC} 1$ and $\mathrm{OC} 2$ respectively. Both graphs show the pressure profiles measured $1.5 \mathrm{~mm}$ downstream of the NGV trailing edge and those obtained with the CFD models 1 and 3 at the same position. During the measurements, the quantity of cooling air introduced into the cavity was sufficiently small $\left(\mathrm{U}_{\mathrm{m}} / \mathrm{U}_{\mathrm{e}}=0.045\right.$ at $\mathrm{OC} 1$ and 0.018 at $\left.\mathrm{OC} 2\right)$ to ensure that any effect of rim seal outflow on the mainstream pressure profile remains weak. The unsteady solution of model 3 was timeaveraged over a period. The circumferential location was nondimensionalised using a fraction of the NGV pitch where the value 0 represents the trailing edge position.

Both at $\mathrm{OC} 1$ and $\mathrm{OC} 2$, the CFD models tend to overpredict the peak-to-peak amplitude of the measured pressure asymmetry though the agreement with the experiments is slightly improved when the Spalart-Allmaras turbulence model is used. This observation must be balanced by the fact that the pressure gradient might be underestimated due to the limited number of pressure taps in the rig. In addition, the experimental data are not perfectly periodic in the circumferential direction and the CFD models do not account for any effect of the ingestion and ejection of flow through the seal gap. Thus, some uncertainty surrounds the determination of the pressure asymmetry. It is also worth pointing out that there is no significant difference between model 1 (NGV only) and the time-average of model 3 (complete turbine stage).

Figure 8 gives the CFD-predicted axial decay of the circumferential pressure variation due to the NGVs at $\mathrm{OC1}$ (using models 1 and 3 with a Spalart-Allmaras turbulence model). For the unsteady solution, the pressure profiles were time-averaged over a period. The circumferential pressure variation is plotted over a maximum $13.2 \mathrm{~mm}$ distance downstream of the NGVs because of the presence of the rotor blades. The position of the axial rim seal is also represented in the figure. Again there is little difference between modelling the vane only or the whole turbine stage with the unsteady model giving a slightly faster decay of the NGV pressure asymmetry. The influence of the blades on the time-averaged pressure field appears to be limited to near the blade leading edge.

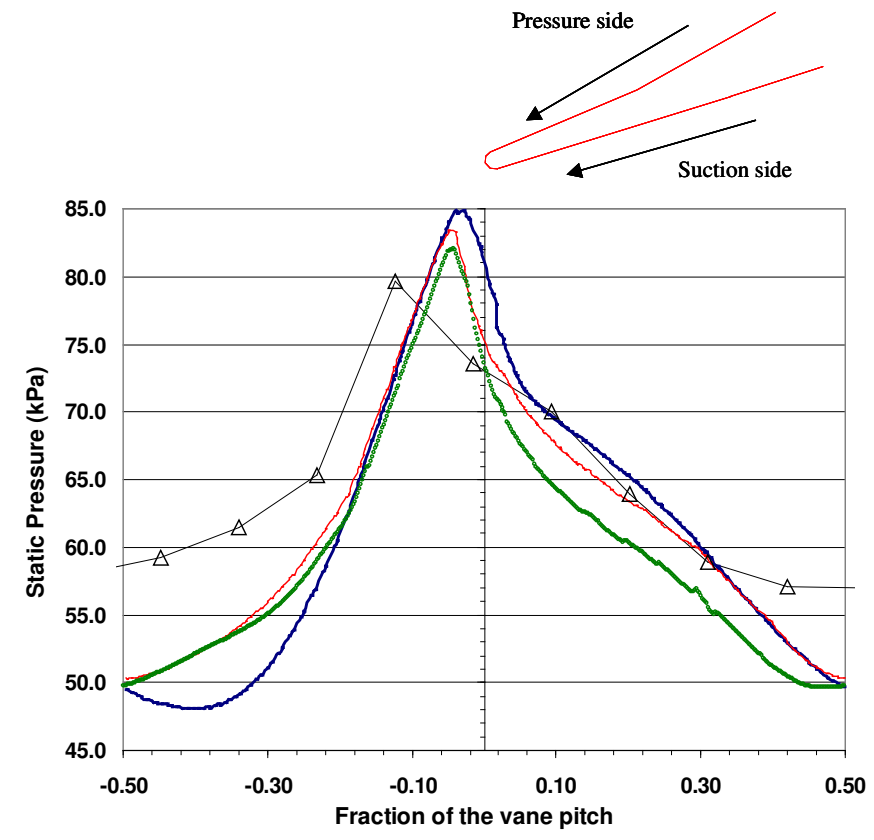

(a) design condition OC1

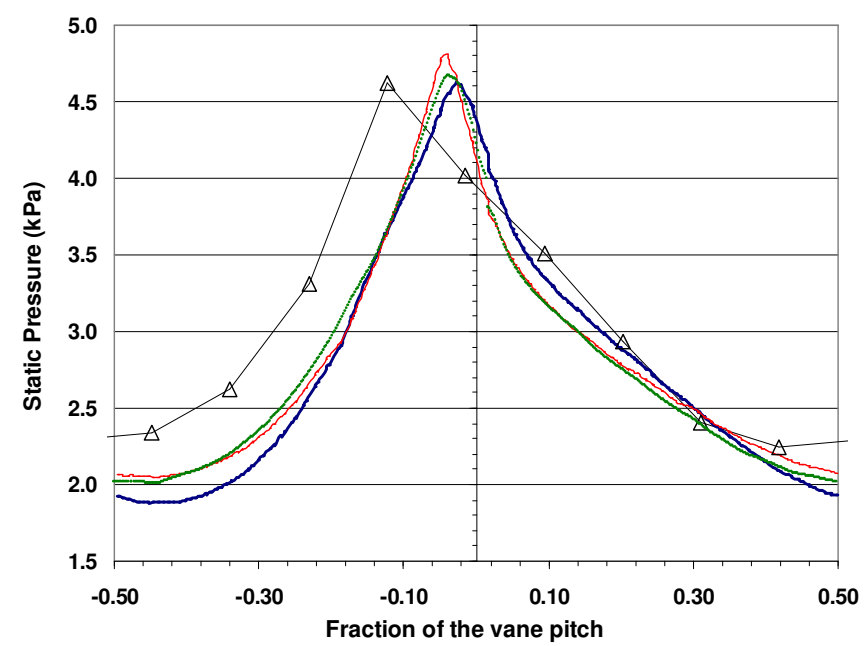

(b) low-pressure condition OC2

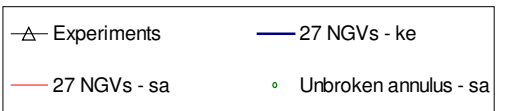

Fig. 7. Comparison with annulus pressure measurements

( ke : k- $\varepsilon$ turbulence model / sa : Spalart-Allmaras turbulence model)

The pressure distributions obtained with model 1 at different axial positions downstream of the NGVs were Fourieranalysed and expressed as: 


$$
p_{\theta}=p_{0}+\sum_{k} A_{k} \times \cos \left(\theta+B_{k}\right)
$$

where $p_{\theta}$ is the static pressure at the angular location $\theta$ with $A_{k}$ and $B_{k}$ the amplitude and phase of the $k^{\text {th }}$ harmonic function. Axial decay of the 4 first harmonic components $A_{k}$ is shown in Fig. 9. At the seal gap, results suggest that the first harmonic is likely to dominate the NGV pressure asymmetry. Also included in this figure is the potential flow approximation previously used by Chew et al [7] and Hills et al [20]. According to this analytical model, the first harmonic decays as $e^{-k x}$ where

$$
k=\frac{N}{r} \frac{\sqrt{\left(1-M^{2}\right)}}{\left(1-M_{z}^{2}\right)}
$$

$\mathrm{N}$ being the number of vanes (or blades), $\mathrm{r}$ the radius, $\mathrm{M}$ the Mach number (relative for the rotor) and $\mathrm{M}_{\mathrm{z}}$ the Mach number based on the axial component of velocity. It can be seen that the potential flow approximation succeeds reasonably well in predicting the decline of the first harmonic given by the CFD calculations. It should also be noted that the pressure asymmetry is still significant at the leading edge of the rotor blades (13.2 mm downstream of the NGVs). Thus some effect of the NGV flow field on the blade flow can be expected.

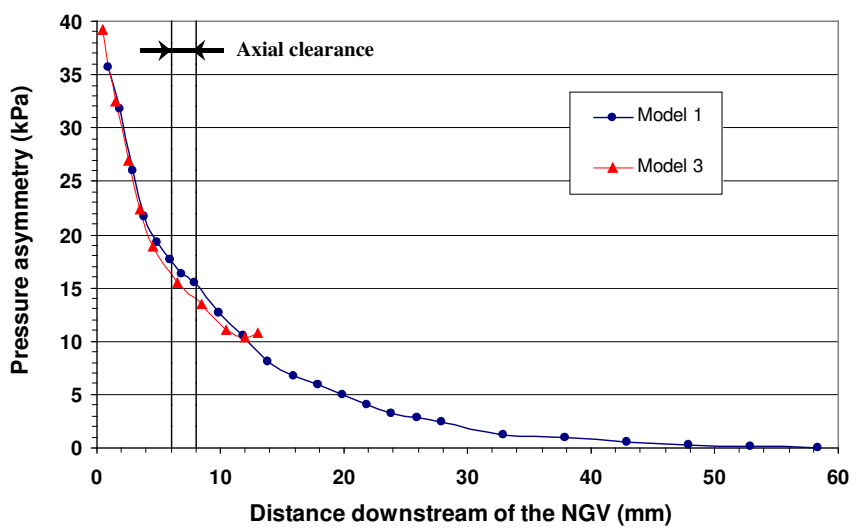

Fig. 8. Axial decay of the NGV pressure asymmetry at the design condition OC1 with the Spalart-Allmaras turbulence model

Figures 10 and 11 focus on the pressure asymmetry generated by the rotor. Despite being much smaller than that produced by the NGV, the pressure gradient due to the rotating blades could have a significant effect on ingestion. Its axial decay upstream of the blade is shown in Fig. 10 at OC1 from the CFD models 2 and 3 (still using the Spalart-Allmaras turbulence model). For model 3, these results were obtained by averaging the time-dependent pressure profiles over a period in the rotating reference frame. The two models do not agree very well: the unsteady model results in an amplitude of the rotor pressure asymmetry twice as high as that given by the steady model 2. As noted above, the pressure asymmetry due to the NGVs is still significant at the rotor blade leading edge, and the unsteady calculation confirms that this effects the rotor flow. The variations of the 4 first harmonic components $A_{k}$ of the rotor pressure asymmetry from model 2 are given in Fig. 11. The axial decay of the first harmonic is also compared with the potential flow approximation given by Eq. 2 . The potential flow looks to yield to a significant underprediction of the rotor pressure asymmetry decay.

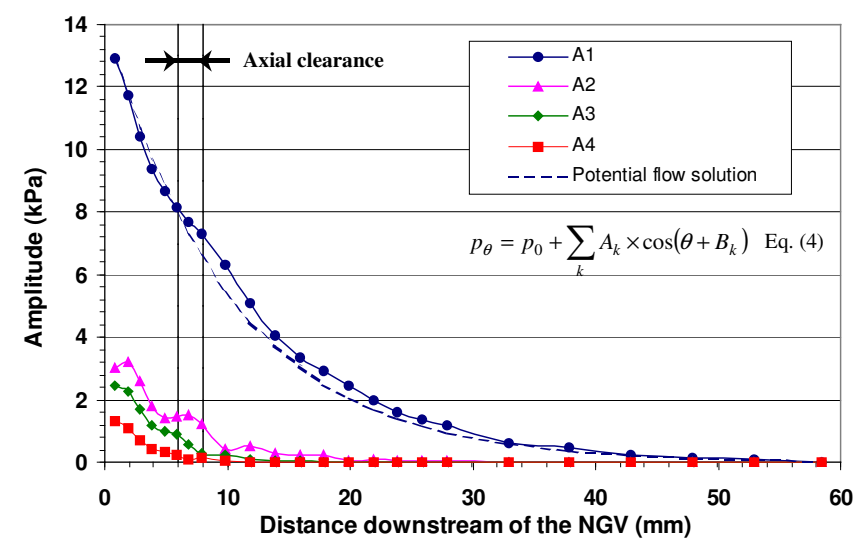

Fig. 9. Axial decay of harmonic components of the NGV pressure asymmetry at the design condition $\mathrm{OC} 1$ with the Spalart-Allmaras turbulence model

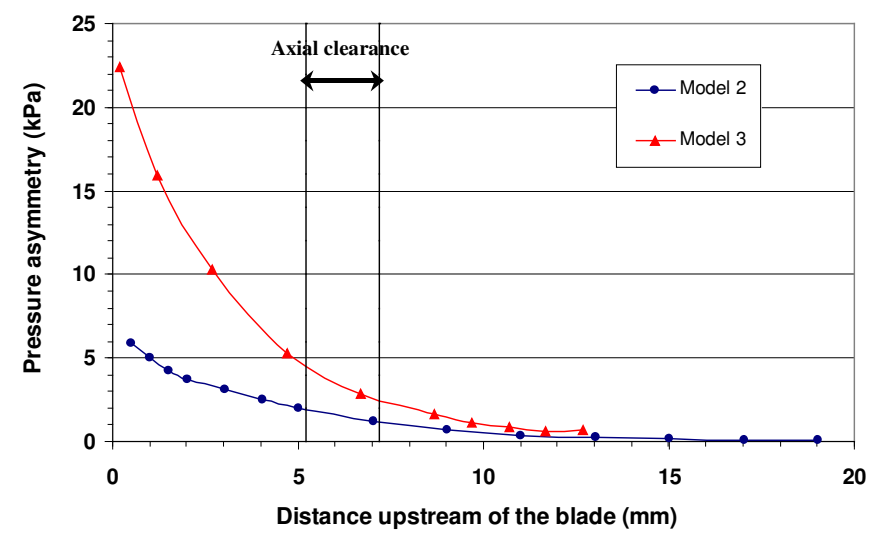

Fig. 10. Axial decay of the rotor pressure asymmetry at the design condition OC1 with the Spalart-Allmaras turbulence model 


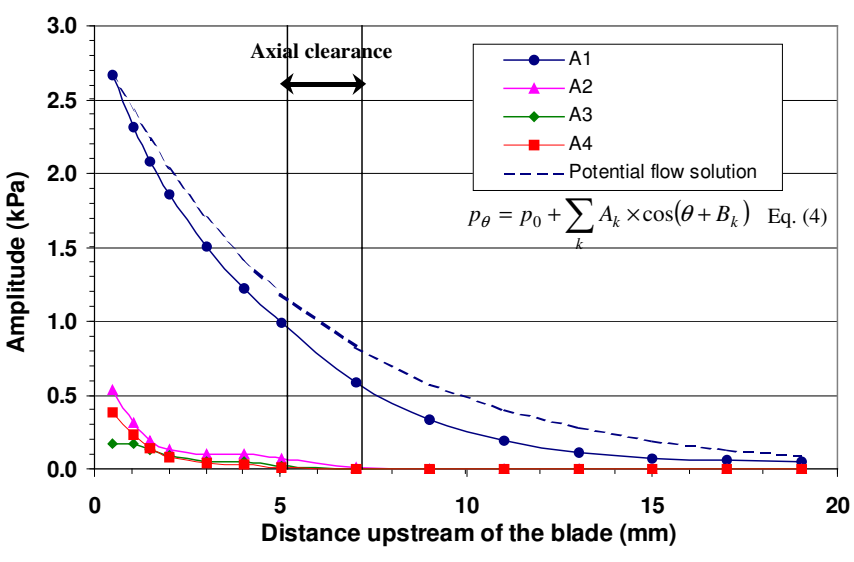

Fig. 11. Axial decay of harmonic components of the rotor pressure asymmetry at the design condition OC1 with the Spalart-Allmaras turbulence mode

\section{INGESTION MODELLING}

The circumferential pressure asymmetries given by the CFD model in the previous section are now used in conjunction with the simple rim sealing model presented by Hills et al [11]. Solutions for the simple model are obtained from a stand-alone computer program. The resulting predictions for sealing effectiveness for the present turbine are compared with the concentration measurements given in section 2 .

The simple model can be viewed as an extension of the widely used orifice model that estimates flow through the seal at each circumferential location using simple orifice theory. The extended model involves inclusion of some inertial effects and involves numerical solution of the following equation:

$$
\rho l\left(\frac{\partial}{\partial t}+\frac{V_{\theta}}{r_{o}} \frac{\partial}{\partial \theta}\right) U+\frac{\rho U^{2}}{2} C_{h} \operatorname{sgn}(U)=\Delta p
$$

Here $\mathrm{C}_{\mathrm{h}}$ is a loss coefficient, $l$ is an appropriate length scale (in the $\mathrm{r}-\mathrm{z}$ plane), $\mathrm{r}_{\mathrm{o}}$ is the inner annulus wall radius which is taken to equal the seal radius, $V_{\theta}$ is the tangential velocity (assumed uniform), $\mathrm{U}$ is the mean velocity through the seal, and $\Delta \mathrm{p}$ is the pressure in the cavity minus the annulus pressure. Equation (6) is solved numerically for $\mathrm{U}$ with specified $\Delta \mathrm{p}$, which in the present case is periodic in time. The numerical solution uses central differences for derivatives with respect to $\theta$ and first order implicit time stepping. Numerical experiments were performed to ensure that numerical errors were insignificant.

Mass flows into and out of the cavity are then calculated from the computed solutions for $\mathrm{U}$, which requires specification of seal clearance $\left(s_{c}\right)$ and discharge coefficient $\left(C_{d}\right)$. An estimate of the sealing effectiveness is then given by

$$
\Phi=m /\left(m+m_{\text {in }}\right)
$$

where $\mathrm{m}$ is the net mass flow rate through the seal and min is the ingestion flow rate. This estimate is based on a fully mixed assumption for the flow in the cavity. It does not fully account for the unsteady effects shown in previous CFD studies.

For the calculations described below $\mathrm{C}_{\mathrm{h}}$ was taken as 1 and discharge coefficients were obtained from the correlations given by Chew et al [7]. These give the discharge coefficient as a function of the ratio of mean seal velocity to the axial component of the annulus velocity $\mathrm{U}_{\mathrm{m}} / \mathrm{U}_{\mathrm{e}}$. Following the practice of Hills et al, here $l$ was set to $\mathrm{C}_{\mathrm{d}} \cdot \mathrm{s}_{\mathrm{c}}$ and $\mathrm{V}_{\theta}$ was set to the estimated swirl velocity for the annulus flow above the seal. Sinusoidal variations of annulus static pressure are assumed with uniform and steady cavity pressure. The cavity pressure is varied to obtain results for a range of sealing mass flows. To show sensitivity, a second set of calculations is presented with $\mathrm{V}_{\theta}$ set to half the value estimated for the annulus freestream.

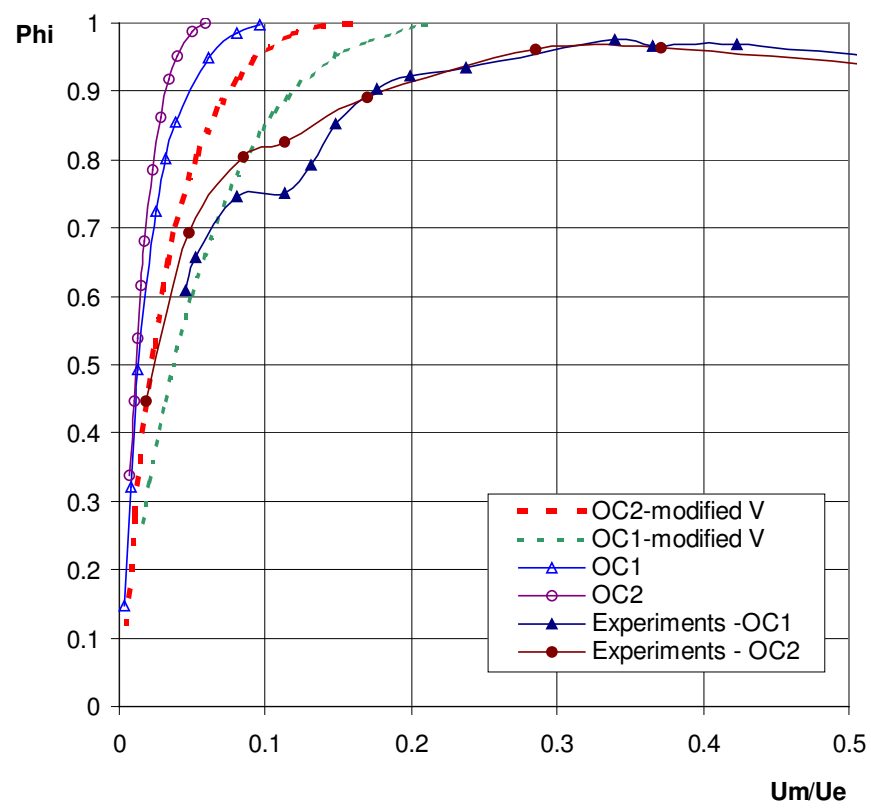

Fig. 12. Comparison of simple model for gas ingestion with measurements

Figure 12 shows a comparison of the simple model predictions with the experimental concentration measurements. For the model, pressure asymmetries for the NGVs and blades were estimated from the unsteady, stage CFD calculation. The measurements are presented as the sealing effectiveness estimated from the gas concentrations at $\mathrm{r} / \mathrm{r}_{\mathrm{o}}=0.92$. It may be seen that the measurements generally show more ingestion than that calculated with the model, particularly at higher sealing flow rates. However the degree of sensitivity to operating conditions is consistent with the experiments. These results agree with the trends found by Hills et al [11] who showed a similar but less pronounced underprediction of ingestion for their configuration. Hills et al also showed the importance of 
the parameters $\Delta \mathrm{p} / \rho_{\mathrm{e}} \mathrm{U}_{\mathrm{e}}^{2}$ and $\mathrm{N}\left(\mathrm{s}_{\mathrm{c}} / \mathrm{r}_{\mathrm{o}}\right)\left(\mathrm{V}_{\theta} / \mathrm{U}_{\mathrm{e}}\right)$ in the model. Estimating these for the rotor pressure asymmetry in Hills et al's configuration gives $\Delta \mathrm{p} / \mathrm{\rho}_{\mathrm{e}} \mathrm{U}_{\mathrm{e}}^{2} \approx 0.2$ and $\mathrm{N}\left(\mathrm{s}_{\mathrm{c}} / \mathrm{r}_{\mathrm{o}}\right)\left(\mathrm{V}_{\theta} / \mathrm{U}_{\mathrm{e}}\right) \approx 0.01$, while for the present configuration the corresponding values are 0.11 and 0.9 for $\mathrm{OC} 1$ and 0.13 and 0.5 for OC2. With this change in parameters the effects of the rotor pressure asymmetry would be expected to be considerably reduced for the present configuration. Although not shown on the figure, further results from the model for $\mathrm{OC} 1$ indicate that the influence of the rotor pressure asymmetry is rather small in this case. Further comparison with Hills et al's results shows that the model correctly predicts that the present configuration gives better sealing (for the same value of the velocity ratio), but overestimates this effect.

Considering these results and the uncertainties in both the model and the experimental conditions it was postulated that the simple model, with the initial choice of parameters overestimated the inertial effects represented by the first term in Eq. (6). This could be due to the effects of the hub boundary layer and/or the lower value of tangential velocity of the sealing flow. Annulus flow entering the seal will come from the boundary layer on the stationary hub and may have a substantially lower tangential velocity than that estimated above. The second set of results in Fig. 12 confirms the sensitivity to $V_{\theta}$. The differences between calculated and measured values are consistent with the swirl velocity of the seal flow decreasing as the sealing flow rate increases (and hence ingestion of highly swirling annulus gas reduces) It is expected that recalibration of the model could give considerably better agreement with the measurements. However, it should also be noted that both the present study, and that of Hills et al have considered only a simple axial seal. Calibration against data for other types of seal is also required.

\section{CONCLUSIONS}

Measurements showing ingestion of mainstream gas into a turbine disc cavity have been obtained for a single stage turbine. Pressure measurements within the disc cavity show that for low sealing flows ingestion of the highly swirling annulus air leads to increased levels of swirl (and hence radial pressure gradients within the cavity. Gas concentration measurements also show ingestion of mainstream gas, and pressure measurements on the annulus hub show the circumferential pressure asymmetry just downstream of the NGVs. Comparison of the gas concentration measurements at two different operating points shows that the seal to annulus flow velocity ratio is a useful correlating parameter. These measurements will be useful in further evaluation of CFD and other models for rim sealing.

CFD studies of the annulus flow show fair agreement with the pressure measurements and estimates of the pressure asymmetry decay rates given by a linear potential flow solution. The pressure asymmetry at the seal due to the NGVs is only slightly affected by the presence of the rotor blades. However, the pressure asymmetry due to the rotor is very significantly modified by the potential field due to NGVs. The pressure asymmetry levels given by the CFD model were used in the simple ingestion model described by Hills et al [11]. This model, using the same 'model constants' as Hills et al significantly underestimated the ingestion levels for the present case. However, experimental trends are consistent with the measurements and recalibration of the model can be expected to give considerable improvement. The model shows strong sensitivity to the swirl velocity assumed for the seal flow.

Note that the present results should not be generalised to other turbine rim seals without careful consideration. Proximity of the seal to the vanes and blades will clearly have a significant effect, as will the number of blade and vanes. Rim seal geometry is also likely to be important. While Mach number effects appear relatively weak in the present case, the axial decay rate of the circumferential pressure asymmetries does vary with Mach number, and this could be more important in other circumstances. Clarification of these effects can be expected as further experimental and CFD results become available.

\section{ACKNOWLEDGMENTS}

The authors wish to express their thanks to Rolls-Royce plc and Alstom for their support in the research work presented in this paper.

\section{REFERENCES}

[1] Campbell, D.A., 1978, "Gas turbine disc sealing system design," Proc. AGARD conf. on seal technology in gas turbine engines, AGARD-CP-237.

[2] Abe, T., Kikuchi, J. and Takeuchi, H., 1979, "An investigation of turbine disc cooling," Paper GT30, 3rd CIMAC Congress, Vienna.

[3] Kobayashi, N., Matsumato, M. and Shizuya, M., 1984, "An experimental investigation of a gas turbine disc cooling system," ASME J. Engng Gas Turbines and Power, 106, pp. 136-141.

[4] Phadke, U.P. and Owen, J.M., 1988, "Aerodynamic aspects of the rim sealing of gas turbine rotor-stator systems parts 1-3," Int. J. Heat and Fluid Flow, 9, pp. 98-117.

[5] Dadkhah, S., Turner, A.B. and Chew, J.W., 1991, "Performance of radial clearance rim seals in upstream and downstream rotor-stator wheelspaces," ASME paper 91-GT-32. (Also ASME J. Turbomachinery, 114, 439-445.)

[6] Hamabe, K. and Ishida, K., 1992, "Rim seal experiments and analysis of a rotor-stator system with non-axisymmetric main flow," ASME paper 92-GT-160.

[7] Chew, J.W., Green, T. and Turner, A.B., 1994, "Rim sealing of rotor-stator wheelspaces in the presence of external flow," ASME paper 94-GT-126.

[8] Green, T. and Turner, A.B., 1992, "Ingestion into the upstream wheelspace of an axial turbine stage," ASME paper 92-GT-303.

[9] Bohn, D., Rudzinsky, B., Surken, N. and Gartner, W., 2000, "Experimental and numerical investigation of the influence of 
rotor blades on hot gas ingestion into the upstream cavity of an axial turbine stage," ASME paper 2000-GT-284.

[10] Roy, R.P., Xu, G., Feng, J. and Kang, S., 2001, "Pressure field and main stream gas ingestion in a rotor stator disc cavity," ASME Turbo Expo paper 2001-GT-564.

[11] Hills, N.J., Chew, J.W. and Turner, A.B., 2001, "Computational and mathematical modelling of turbine rim seal ingestion," ASME Turbo Expo paper 2001-GT-204 (Also to be published in ASME J. Turbomachinery).

[12] Turner, A.B., Davies, S.J., Childs, P.R.N., Harvey, C.J., and Millward, J.A., 2000, "Development of a novel gas turbine driven centrifugal compressor," Proc Instn Mech Engrs, 214, Part A.

[13] Karman, T. Von, 1921, "Uber Laminare und Turbulente Reibung," Z. angew. Math. Mech., 1, pp. 233-252.

[14] Pincombe, J.R. and El-Oun, Z., 1986, Unpublished work. [15] Vaughan, C, 1987, "A numerical investigation into the effect of an external flow field on the sealing of a rotor-stator cavity," Ph.D. thesis, University of Sussex, Brighton, England.

[16] Owen, J.M. and Rogers, R.H., 1989, Flow and Heat Transfer in Rotating-Disc Systems. Volume 1 - Rotor-Stator Systems, Research Studies Press Ltd, Taunton, Somerset, England.

[17] Daily, J.W., Ernst, W.D. and Asbedian, V.V., 1964, "Enclosed rotating discs with superimposed throughflow," Dept. Civil Engng, Hydrodyn. Lab. MIT Rep. No.64.

[18] Gambit 1, 1998, Modeling Guide, Fluent Inc.

[19] Fluent 5, 1998, User's Guide, Fluent Inc.

[20] Hills, N.J., Chew, J.W., Green, T., and Turner, A.B., 1997. Aerodynamics of turbine rim-seal ingestion. ASME paper 97-

GT-268. 